Abstract G319(P) Table 1 Salient results from the survey $(n=51)$

\begin{tabular}{|c|c|c|c|c|}
\hline Survey question (shortened for abstract) & yes & No & undecided & $\begin{array}{l}\text { P value (chi } \\
\text { square test) }\end{array}$ \\
\hline Was the scan useful? & $92 \%$ & - & $8 \%$ & $<.001$ \\
\hline Did the scan reassure you? & $100 \%$ & - & - & $\mathrm{n} / \mathrm{a}$ \\
\hline $\begin{array}{l}\text { Would the clinician's explanation without } \\
\text { echo be reassuring? }\end{array}$ & $14 \%$ & $84 \%$ & $2 \%$ & $<.001$ \\
\hline $\begin{array}{l}\text { Do babies with benign/innocent/normal } \\
\text { murmur need an echo? }\end{array}$ & $94 \%$ & - & $6 \%$ & $<.001$ \\
\hline
\end{tabular}

had echocardiograms for asymptomatic heart murmurs which then proved to be benign.

Methods All new referrals for 'asymptomatic heart murmurs' to the paediatric cardiac clinic, run by a paediatrician with cardiology expertise, over a one-year period were reviewed. The parents of children with normal echocardiograms were requested to answer a questionnaire that elicited their experience of the echocardiogram and its impact on their concerns. Permission for this study was obtained, and consent sought from contacted parents.

Results 166 new patients attended the clinic during the study period, $67 / 166$ were for asymptomatic heart murmurs. 58/67 of these patients had normal echoes. Among the 58patients, 51 were contacted by telephone for the survey (Table 1). None of these children had any repeat consultations for the murmur, and parents were convinced that the echo gave them the reassurance that they badly needed. See table.

Conclusions Our study concluded echocardiograms provide parents with a satisfactory conclusion to the consultation. This may be a cost-effective method in reducing repeat consultations for the same concerns.

\section{G320(P) SEPTIC BABY; HAVE YOU CONSIDERED PARECHOVIRUS MENINGITIS?}

J Williams, E McCully. Paediatric Department, James Cook University Hospital, Middlesbrough, UK

\subsection{6/archdischild-2015-308599.297}

Introduction "Febrile baby" is a common presentation to paediatric departments. In young babies paediatricians are likely to perform a full septic screen to ascertain the source of the temperature. Part of this process involves requesting the correct tests for the best chance of achieving a diagnosis. We discuss three cases with a diagnosis that is perhaps not often considered yet may have potential consequences for development.

Case presentation

Three babies presented in the neonatal period with symptoms including temperature, poor perfusion, rash, shortness of breath and apnoea. All three were judged to be cardiovascularly unstable and received fluid boluses. They all had unremarkable CRP results (maximum $14 \mathrm{mg} / \mathrm{L}$ ). CSF demonstrated raised protein in all three but low white cell count (maximum $3 \times 1000000 / \mathrm{L}$ ). One of the babies required intubation and ventilation for three days for apnoeas. All of the babies improved clinically as soon as they became afebrile (around 3 days after admission). All babies were PCR positive for parechovirus on CSF.
Discussion There are over ten types of parechovirus identified with type 3 most commonly associated with neonatal sepsis. Over $90 \%$ of five year olds have experienced parechovirus as a mild gastrointestinal or respiratory illness. In babies under 3 months of age it is more likely to present more dramatically. It is spread in respiratory droplets, saliva and faeces. Low CSF WCC and raised protein are typical findings. Management is supportive and there is no vaccine. Neurodevelopmental delay has been reported following the illness and animal data suggests persistent presence in CNS causing ongoing inflammation.

Conclusion When assessing and investigating a febrile baby sending a CSF PCR for parechovirus may yield a result in a patient with otherwise unremarkable laboratory investigations. This diagnosis is important as it has the potential to cause neurodevelopmental problems and as such these patients may warrant follow up.

\section{G321(P) FIX FREDDIE!}

${ }^{1} \mathrm{~F}$ Cleugh, ${ }^{1} \mathrm{~A}$ Langseth, ${ }^{2} \mathrm{C}$ Clements, 'M Salam. 'Paediatric Emergency Department, Imperial College Healthcare NHS Trust, London, UK; ${ }^{2}$ Paediatrics, Evelina Children's Hospital, London, UK

\subsection{6/archdischild-2015-308599.298}

Background Facing higher than average unscheduled care use in a busy inner city paediatric unit, with a significant proportion of low acuity conditions, a need to become proactive in tackling the pressure was recognised.

Collaborated as part of new innovative integrated paediatric care model with puppet company to produce Fix Freddie! Pilot tour Spring 2014.

Objectives Better understanding of how local community accesses children's unscheduled care

- bringing together communities and professionals across the whole system, to support families in feeling confident to navigate system and care for their children's health needs

- reduce pressures on the local emergency and urgent care system

Methods Explored different settings and workshop styles (Table 1).

Parents/carers asked to complete a pre show questionnaire. After the show, explored issues with:

- small parent focus groups

- classroom-based discussion and picture drawing

- fete style event with informal conversations with professionals 
Abstract G321(P) Table 1 Pilot tour explored different settings and workshop styles

\begin{tabular}{|c|c|c|}
\hline Settingand Event & Childaudience & Adult audience \\
\hline Primary school & 150 (5-7 year olds) & 30 parents \\
\hline 1 day, 3 shows & 120 (7-9 year olds) & 15 teachers \\
\hline $\begin{array}{l}\text { Children's Centres } \\
2 \text { days, } 3 \text { shows }\end{array}$ & 3- (0-4 year olds) & $\begin{array}{l}35 \text { parents } \\
3 \text { nursery nurses }\end{array}$ \\
\hline $\begin{array}{l}\text { Community Fete Style Events } \\
2 \text { days, } 5 \text { shows }\end{array}$ & $\begin{array}{l}29 \text { ( } 0-5 \text { year olds) } \\
35 \text { ( }>5 \text { year olds) }\end{array}$ & 51 parents and friends \\
\hline
\end{tabular}

Feedback obtained with Post-It comments on "Freddie Feedback” poster.

Information leaflet distributed with advice about where to seek advice, self management, and information about local services.

Filmed to capture impact of events on children, parents and professionals.
Results Pre show questionnaire

Completed by 46 parents of 85 children. 53\% white british; 47\% diverse ethnic mix.

Chart A how seek child health advice - 85\% GP, 21\% ED, $42 \%$ family and friends, $37 \%$ internet.

Chart B services use when worried - 89\% GP, 52\% ED

Abstract G321(P) Table 2

\section{Fix Freddie Feedback}

\section{Structured under headings "What I Liked" "What I Learnt" "What I Will Take Away" "What I Binned"}

\begin{tabular}{|c|c|}
\hline What I Liked & $\begin{array}{l}\text { "Puppet show great to help kids understand } \\
\text { different medical services - session after with } \\
\text { doctors was really interesting" } \\
\text { "Excellent parent info session, more please" } \\
\text { "Leaflet is perfect for parents" " } \\
\text { "Sessions like this for new parents would be } \\
\text { really useful" } \\
\text { "The show was amazing- my } 11 \text { month old was } \\
\text { transfixed." }\end{array}$ \\
\hline What I Learnt & $\begin{array}{l}\text { "I learnt where to take my children if my GP is } \\
\text { closed" } \\
\text { "I learnt not to call } 999 \text { for not important } \\
\text { things, instead call } 111 \text { " }\end{array}$ \\
\hline What I Will Take Away & $\begin{array}{l}\text { "Keep children at home rather than rushing to } \\
\text { the GP" } \\
\text { "The service that NHS111 offers" }\end{array}$ \\
\hline What I Binned & I was sad when Freddie got hurt" \\
\hline
\end{tabular}




\section{Chart A Showing How Many of the 46 Parents Surveyed in Pre Show Questionnaire Sought Health Advice From the Following Sources}

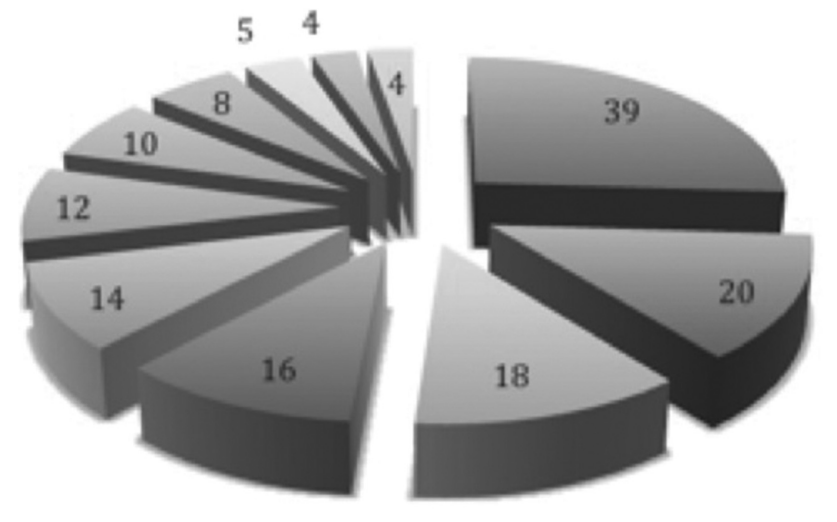

$$
\begin{aligned}
& \text { = GP } \\
& \text { = Friend/relative } \\
& \text { = Internet } \\
& \text { = HV/school nurse } \\
& \text { = Pharmacist } \\
& \text { = Walk in centre } \\
& \text { = A\&E } \\
& \text { = NHS111 } \\
& \text { - School/nursery } \\
& \text { = Out of hours } \\
& \text { = Practice nurse }
\end{aligned}
$$

\section{Chart B Showing How Many of the 46 Parents Surveyed in Pre Show Questionnaire Used the Following Services}

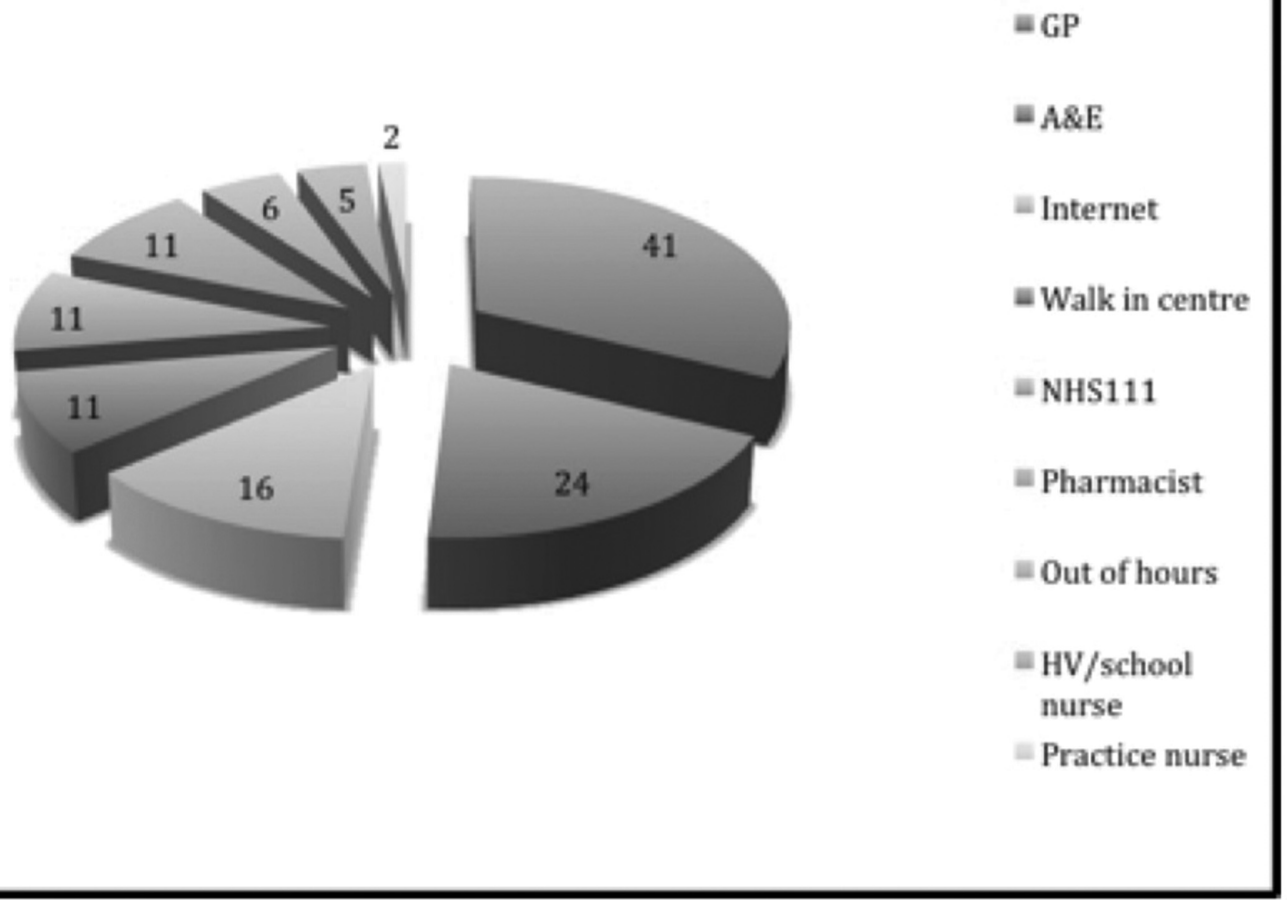

Abstract G321(P) Charts A and B

Parents most consistently worried by fever, 52\% would seek GP review 41\% would go to A\&E. Other concerns included cough, vomiting, diarrhoea, abdominal pain.

Attended ED and the GP with similar illnesses.

$26 \%$ reported issues in accessing care, primarily lack of same day GP appointments.

Key themes surfaced from Fix Freddie! Feedback (Table 2)
- Better understanding of local services available, notably about 111

- Improved knowledge and confidence about self managing minor illnesses and injuries

- Additional awareness raised about safety at home

- General positive feedback for puppet show and events

Conclusion Fix Freddie! has provided a fun and engaging way to make new connexions across the whole system, facilitating 
co-design of local solutions to problems of healthcare accessibility and confidence in self management. Local CCG commissioners are now funding a wider local tour and we are working on next steps to broaden reach of the events.

\section{G322(P) THE DEVELOPMENT OF A PAEDIATRIC SHORT STAY UNIT}

RC Mitchell, L Watt, S Beadle, S Harris, M Bearsmore-Rust, O Akindolie. Department of Ambulatory Paediatrics, Kings College Hospital NHS Foundation Trust, London, UK

10.1136/archdischild-2015-308599.299

Aims There has been pioneering reshaping of our hospital's ambulatory paediatric services over the last year. In line with the RCPCH report 'Short Stay Paediatric Assessment Units', published in 2009, a paediatric short stay unit (PSSU) opened in July 2014, for children needing admission for less than 48 h. It is a consultant delivered service, which aims to meet and exceed the RCPCH 'Facing the Future' standards of care.

Methods Activity data for the first 5 months has been analysed and the impact upon other paediatric services assessed. Patient experience has also been evaluated.

Results To date, 466 patients have been admitted to PSSU with a median length of stay of $18 \mathrm{~h}$. Elsewhere in the trust, there have been fewer general paediatric bed days (1233) since PSSU opening, compared to 1548 for the same period last year. Since PSSU opening, only 1 patient has been 'treated and transferred' to another hospital from PED due to lack of capacity, compared to 10 for the same period last year. Patient satisfaction questionnaires have reported that $76 \%$ of families would recommend PSSU to friends and family if they needed similar care or treatment. The comments from patients and their families about PSSU have been overwhelmingly positive (Figure 1).

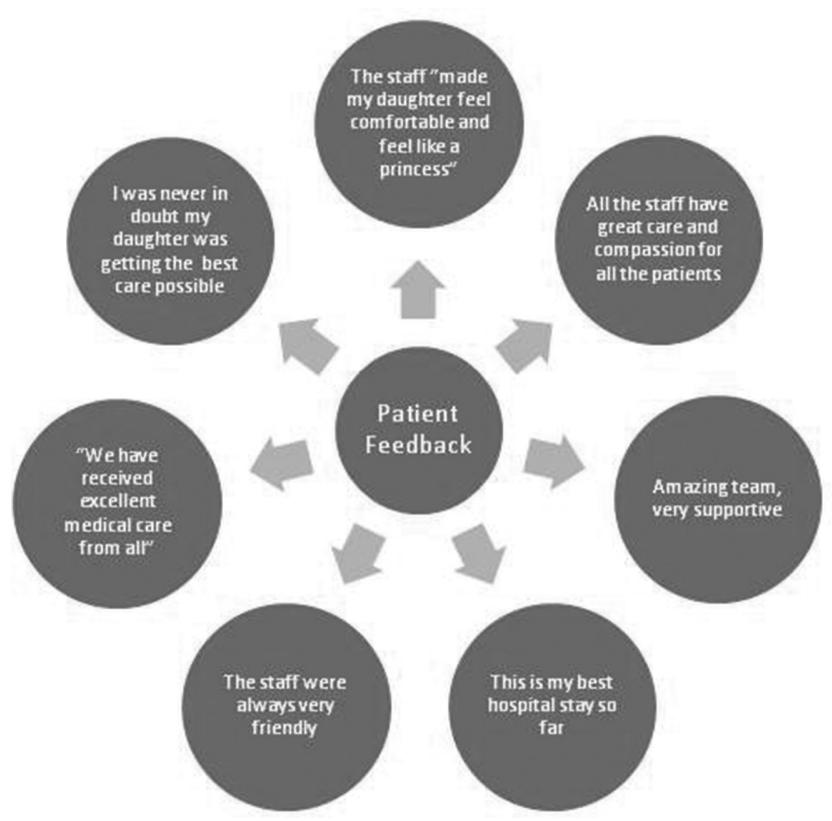

Abstract G322(P) Figure 1 Examples of patient feedback collected in September 2014
Conclusion PSSU has been phenomenally successful in streamlining the patient journey for children requiring hospital admission for less than $48 \mathrm{~h}$. There have been significant secondary gains elsewhere, with reduced numbers of patients needing transfer to other hospitals from PED due to lack of capacity, and increased numbers of inpatient beds for speciality patients. The model of a paediatric short stay unit is here to stay; as was highlighted by 'Facing the Future' publication, acute paediatric care should be delivered in a specialised setting, fronted by senior staff who truly believe in the service. This PSSU is one example of this, as a successful expansion of our ambulatory paediatrics service.

\section{G323(P) TRANSCUTANEOUS BILIRUBIN MEASUREMENT IN NEONATES WITH JAUNDICE REQUIRING PHOTOTHERAPY}

BG Fisher, R Lakshman. Department of Paediatrics, West Suffolk NHS Foundation Trust, Bury St Edmunds, UK

\subsection{6/archdischild-2015-308599.300}

Background UK guidelines advocate the use of transcutaneous bilirubin (TCBR) estimation in neonates with jaundice aged $>24$ $\mathrm{h}$ with a gestational age of $\geq 35$ weeks, but not in neonates who have had phototherapy, as there is a more rapid fall in dermal vs. serum bilirubin with phototherapy. A recent study demonstrated that whilst TCBR underestimated SBR within the first 8 $\mathrm{h}$ after phototherapy, its accuracy returned to pre-treatment values after $24 \mathrm{~h}$. This suggests a possible role for TCBR monitoring in infants who have had phototherapy $>24 \mathrm{~h}$ ago, reducing the number of both blood tests and hospital visits.

Aim To compare TBCR and SBR measurements before, during and after phototherapy in neonates.

Methods This was a prospective observational study at a UK district general hospital. Participants were all neonates admitted to the neonatal unit or postnatal ward who required an SBR measurement for jaundice monitoring as per UK guidelines. TBCR measurement was performed using a Dräger Jaundice Metre JM-103 within $10 \mathrm{~min}$ of the SBR sampling. SBR was determined by blood gas analysis. Safety margins (mean difference $-2.33 \times \mathrm{SD}-50$ ) were calculated for TCBR readings during phototherapy to correctly assign $99 \%$ of neonates to stop receiving phototherapy, i.e. SBR $>50 \mu \mathrm{mol} / \mathrm{l}$ below the treatment threshold.

Results Pilot data: 8 neonates (gestation $34+4$ to $42+0,4$ male) had a total of 11 simultaneous measurements. Measuring TCBR on the forehead, the mean (SD) difference (TCBR - SBR) before phototherapy was $-45 \mu \mathrm{mol} / \mathrm{l}(17 \mu \mathrm{mol} / \mathrm{l})$, during phototherapy was $-102 \mu \mathrm{mol} / \mathrm{l}(8 \mu \mathrm{mol} / \mathrm{l})$, and at $>16 \mathrm{~h}$ after phototherapy was $-48 \mu \mathrm{mol} / \mathrm{l} \quad(6 \mu \mathrm{mol} / \mathrm{l})$. Values were similar measuring TCBR on the sternum. During phototherapy, TCBR levels of $-171 \mu \mathrm{mol} / \mathrm{l}$ below the treatment threshold allowed safe cessation of phototherapy without confirmatory SBR testing.

Conclusion TCBR measurements $>16 \mathrm{~h}$ after phototherapy appear to be equally as accurate as before phototherapy, which could obviate the need for SBR measurement when checking for a rebound rise in bilirubin after stopping phototherapy. More comprehensive data will be collected in time for presentation at the RCPCH Conference. 